concerned with experimental work. Studies of the relationship of social factors and of leucotomy to the experience and complaint of pain, are reviewed and discussed. A concluding section deals with some theories of the nature of pain. The authors tend to support the view of pain as an often psychosocially over-determined but essentially organismal experience and response to threatening or noxious stimuli. Their main resistance is to pain being construed in terms of sensation alone. The book is rounded off by a comprehensive and detailed bibliography and, most useful of all, an index of authors. In the reviewer's opinion this book offers important reading for all students and practitioners.

\section{The Psychiatric Dilemma of Adolescence}

By James F. Masterson, JR. Pp. 217. Boston: Little, Brown. London: J. \& A. Churchill. 1967. \$9.00; 65s.

This book reports a study of the psychiatric state and the family dynamics of 101 adolescent out-patients at first interview. Seventy-two were seen again after $2 \frac{1}{2}$ and 5 years and most of the mothers were interviewed. The patient group was compared with a matched control group. The study was designed to investigate to what extent 'adolescent turmoil', a transient disturbance related to the impact of adolescence on the personality and generally thought to subside with growth and maturity, was a significant factor, and to what extent these patients were suffering from more severe forms of disturbance which did not improve after the conflicts of adolescence had resolved.

The book is divided into six sections, including methodology, dynamic factors, diagnostic categories, clinical outcome, discussion and speculation based on the findings.

Although the author is himself aware of imperfections in methodology, these are not to be discounted, and the rigidity of the Kraepelinian approach to disease as compared with the more fluid Meyerian approach is highlighted in this book. Consequently the validity of the sections concerned with diagnostic labels and their immutability is difficult to interpret. Criteria for inclusion in specific diagnostic categories are unclearly stated and moreover $6 \%$ of the control group were reported as exhibiting schizophrenic symptoms, reflecting perhaps an American bias in diagnosis.

On the basis of his evidence, Professor Masterson's findings suggest that psychiatric disturbance in adolescence is not transient and although the clinical picture may be coloured by 'adolescent turmoil', on emergence from adolescence more clearly differentiated psychiatric disturbance remains apparent.

Although I found the presentation of the study itself could have been clearer if not in book form, the last sections concerned with clinical outcome and speculation were illuminating.

The book is important for those concerned with the problems of adolescence.

\section{Guide to Psychiatry}

By Myre Sim. Second Edition. Pp. xi +1055 . Edinburgh and London: E. \& S. Livingstone. 1967. 60s.

This is the only major English textbook of psychiatry written from a truly eclectic viewpoint. The first edition was enthusiastically received and this edition is an even bigger and better one. In the new preface the author defends the large size of his book both ably and with justification. The text is admirably laid out and makes exceptionally easy and compelling reading. The author writes from a clinically and theoretically erudite and scholarly position. He occasionally quotes at length and unabashedly from other sources but always appropriately and usefully. This new edition represents a bringing up to date of much of his material and the text is liberally laced with references to important research and opinion published over the last 4 years.

In addition to the conventional chapters on aetiological, phenomenological, diagnostic and therapeutic aspects of psychiatric illness, there are lengthy and useful sections dealing with psychosomatic disorders, with social psychiatry and with the legal aspects of psychiatry both here and in the U.S.A. Although in so many ways a beacon of sound clinical sense the author continues to maintain his view that there are never any psychiatric indications for termination of pregnancy. This is extreme and in many people's eyes an unreasonable view. It not only appears out of character but leads to the retention of the section on puerperal psychosis in the chapter on the legal aspects of psychiatry instead of in the clinical section. The concluding and useful biography unfortunately lacks a system of easy reference back to the text.

Pathology Annual, Volume 2, 1967

Series editor: Sheldon C. Sommers. Pp. $x+427$ illustrated. New York: Appleton-Century-Crofts. London: Butterworths. 1967. $£ 5$.

This second volume of a series edited by Sheldon $C$. Sommers is expensive but well printed and bound, and a pleasure to handle. The illustrations are of high quality, printer's errors are few and the index is comprehensive. It will be of particular value to practising morbid anatomists and histopathologists, who will find it an excellent bench reference book when information on the difficult problems encountered in renal and liver biopsy material is required. There is a good summary of the present position regarding sarcoid and lesions which mimic it and an interesting chapter on the relation between fibrocystic disease of the breast, hyperplasia and carcinoma. The histochemistry of the prostate is discussed and an account of recent research given. A well-balanced chapter on the relation of diet to atherosclerosis evaluates the evidence for and against incriminating cholesterol and other derivatives. A useful account of the congenital malformations involving transposition of the great vessels is given by an acknowledged authority on the subject. A particularly good chapter is that on vegetative endocarditis in which a masterly study of the development of our knowledge, the classification, mechanisms and pathogenesis are described. There is a clinicopathological study of renal carcinoma with some interesting statistical information and a chapter on epidemiological and statistical methods as applicable to pathology, particularly cancer. Modern research on connective tissue is described and will supplement Gardner's book on the pathology of the connective tissue diseases. Pituitary tumours, both experimental in animals and those in man, are discussed from the histochemical angle and an account of differential staining methods and hormone studies is included. A translation of Chapter VIII of the 1956 edition of Mason's Tumeurs Humaines, treating of his well-known concepts on naevi and malignant melanomas will be of value to non-French-speaking readers. Finally, there is an amusing playlet, "A Day in the Life of a Hospital Pathologist', which depicts day-to-day problems in running a hospital laboratory, any of which could (and do), equally well arise in its British counterpart. 